\title{
Forecasting US recession with the economic policy uncertainty indexes of policy categories
}

\author{
Kazutaka Kurasawa* \\ Yamanashi Gakuin University, Kofu, Yamanashi, Japan
}

Received: 8 September 2017

Revised: 5 March 2018

Accepted: 5 March 2018

\begin{abstract}
Uncertainty about the future affects economic decisions today since there is an option value to postpone economic decisions. Using the economic policy uncertainty (EPU) indexes of policy categories developed by Baker et al. (2016), this study estimates the probit model to predict the recession probability in the United States, and quantifies the relative significance of the category-specific EPU indexes. The EPU index of national security is found relatively useful as predictors of recession. This category-specific measure of uncertainty provides information about the occurrence of recession that the other variables do not contain.
\end{abstract}

Keywords: US economy; recession; forecasting; probit model JEL Classification Codes: E37, E32, C53

\section{Introduction}

Uncertainty about the future affects economic decisions today since there is an option value to postpone economic decisions. Under uncertainty, households and firms 'wait and see' (Bernanke (1983)); they prefer to suspend durable goods consumption, fixed investment and hiring, which are partially irreversible due to transaction and adjustment costs (Brennan and Schwartz (1985), Mcdonald and Siegel (1986), and Dixit and Pyndyck (1994)). In aggregate economy, the 'wait and see' behaviors of households and firms can generate boom-bust cycles. Empirical studies find the links between uncertainty shocks and macroeconomic outcomes, suggesting that uncertainty can be a useful predictor of economic cycle (Engle and Rangel (2008), Bloom (2009), Born et al. (2013), Fernandez-Villaverde et al. (2011), Handley and Limão (2012), Jones and Olson (2013) and Novy and Taylor (2014)).

Uncertainty is, however, a variable that is difficult to objectively measure since it relates to expectations on how future events will unfold over time. Recent studies apply text search methods to yield less subjective proxies for uncertainty (Alexoupoulos and Cohen (2015),

\footnotetext{
*E-mail: k-kurasawa@ygu.ac.jp.

Citation: Kurasawa, K. (2017) Forecasting US recession with the economic policy uncertainty indexes of policy categories, Economics and Business Letters, 6(4), 100-109.
} 
Boudoukh et al. (2013), Gentzkow and Shapiro (2010), and Hoberg and Phillips (2010)). Among others, Baker et al. (2016) have developed the economic policy uncertainty (EPU) index for the United States and some other countries. The EPU index is mainly based on the relative frequency of key words that appear in major newspapers. Recent econometric studies use the EPU index as a proxy variable for uncertainty.

Since Estrella and Mishkin (1998), financial variables, such as the interest rate spreads, the stock return and the stock market volatility, have been found useful as leading indicators of recession. More recent studies, such as Bluedorn (2016), Liu and Moench (2016) and Nyberg (2018), also find the statistical significance of these financial variables in predicting the onset of recession. In the literature, however, few studies examine the forecasting ability of economic uncertainty beyond the financial variables. Karnizova and Li (2014) assess the marginal forecasting ability of the EPU index, finding that the index is statistically and quantitatively significant in forecasting US recession.

This paper extends Karnizova and Li (2014) and evaluate the potential use of the EPU indexes of policy category in the probit forecasting model. Baker et al. (2016) release nine category-specific EPU indexes - monetary policy, taxes, government spending, health care, national security, entitlement program, regulation, trade policy and severing debt and currency crisis - on monthly basis. We utilize the information from these specific policy areas and assess the potential value of the category-specific EPU indexes. Although the overall EPU index has been found statistically significant in explaining the probability of recession, it is not plausible that all the policy categories are equally useful in forecasting the occurrence of recession. This paper quantifies the relative significance of the category-specific EPU indexes in predicting US recession.

\section{Methods}

Predicting future economic activities is important to all economic agents, such as consumers, firms and governments. In the literature, some forecasting models test the impacts of potential explanatory variables on output growth. Others focus on recession risk and forecast the onset of recession, using a binary variable indicating the periods of recession as a dependent variable. Recession is a more wide-ranging concept describing a country's economic activities than growth slowdown. According to the National Bureaus of Economic Research (NBER) of the United States, recession is defined as a significant decline in economic activities that spread across the economy, lasting more than a few months, normally visible in real GDP, real income, employment, industrial production and wholesale-retail sales (NBER's Business Cycle Dating Committee (2010)). The Organization for Economic Co-Operation and Development (OECD) defines the turning points of business cycle in a similar way (OECD (2013)). Binary forecasting models statistically estimate an overall decline in economic variables, not just a slowdown of a single variable.

Since Estrella and Mishkin (1998), the probit model with financial variables have been widely applied to compute the probability of future recession and test the forecasting performance of the variables. Financial variables, such as the term spread, the corporate spread, the stock return and the stock market volatility, have been found useful in predicting future economic activities (see Wheelock and Wohar (2009) for the recent survey). Using this framework, we quantitatively evaluate the marginal predictive power of the nine categoryspecific EPU indexes beyond the financial variables.

The probit forecasting model first assumes that there is a linear relationship between explanatory variables and an unobserved index that determines the occurrence of recession:

$$
Y_{t+h}=\beta^{\prime} X_{t}+\epsilon_{t}
$$


where $Y_{t+h}$ is an unobservable index that determines whether the economy is in recession at time $\mathrm{t}+\mathrm{h}, X_{t}$ is a vector of explanatory variables including one of the EPU indexes and the financial variables at time $t, \beta$ is a vector of fixed coefficients, $\epsilon_{t}$ is a random variable. The binominal recession indicator $R_{t+h}$ is defined as:

$$
R_{t+h}= \begin{cases}1, & \text { if } Y_{t+h}>0 \\ 0, & \text { if } Y_{t+h} \leq 0\end{cases}
$$

The probability of recession $\mathrm{P}\left(R_{t+h}=1\right)$ is assumed to be in the form of the cumulative normal distribution:

$$
\mathrm{P}\left(R_{t+h}=1 \mid X_{t}\right)=\int_{-\infty}^{\beta^{\prime} X_{t}} \phi(t) d t=\beta^{\prime} X_{t}
$$

where $\phi$ is the standard normal distribution. With the historical data of $R_{t+h}$ and $X_{t}$, we estimate the model by maximizing the likelihood function:

$$
\mathrm{L}=\prod_{R_{t+h}=1} F\left(\beta^{\prime} X_{t}\right) \prod_{R_{t+h}=0}\left[1-F\left(\beta^{\prime} X_{t}\right)\right]
$$

The coefficients in the vector $\beta$ represent the marginal effects of $X_{t}$ on the unobserved index $Y_{t+h}$, or $\beta_{i}=\partial Y_{t+h} / \partial X_{i, t}$, where $\beta_{i}$ is the ith element of $\beta$ and $X_{i, t}$ is the ith independent variable in $X_{t}$. We are, however, more interested in the marginal effects of $X_{i, t}$ on the probability of recession $\mathrm{P}\left(R_{t+h}=1\right)$ :

$$
\partial \mathrm{P}\left(R_{t+h}=1 \mid X_{t}\right) / \partial X_{i, t}=\phi\left(\beta^{\prime} X_{t}\right) \beta_{i}
$$

Since Eq. 5 is conditional on the value of $X_{t}$, the marginal effects are often evaluated at the mean $\bar{X}$ :

$$
\partial \mathrm{P}\left(R_{t+h}=1 \mid \bar{X}\right) / \partial X_{i, t}=\phi\left(\beta^{\prime} \bar{X}\right) \beta_{i}
$$

We also assess the predictive power of the category-specific EPU indexes in terms of the measures of fit. Many fit measures have been proposed for probit and other binary choice models. In this paper, we use the so-called pseudo $R^{2}$ developed by Estrella (1998) and Estrella and Rodrigues (1998):

$$
1-\left(\frac{\ln L}{\ln L_{0}}\right)^{-(2 / n) \ln L_{0}}
$$

where $\mathrm{L}$ is the unconstrained maximum value of the likelihood function, $L_{0}$ is the maximum value of the likelihood function under the constraint that all the coefficients in the vector $\beta$ are zero, and $\mathrm{n}$ is the number of observations in the sample. This likelihood ratio index intuitively corresponds to the widely known coefficient of determination, or $R^{2}$, in linear regression analysis; the pseudo $R^{2}$ is constructed to be bounded between zero and one.

An alternative fit measure that is more linked to forecasting performance has been suggested by Ben-Akiva and Lerman (1985) and Kay and Little (1986):

$$
\frac{1}{n} \sum_{t=1}^{n}\left[R_{t+h} \hat{P}\left(R_{t+h}=1 \mid X_{t}\right)+\left(1-R_{t+h}\right)\left(1-\hat{P}\left(R_{t+h}=1 \mid X_{t}\right)\right)\right]
$$

where $\hat{P}\left(R_{t+h}=1 \mid X_{t}\right)$ is the predicted probability of recession at time $\mathrm{t}+\mathrm{h}$ conditional on $X_{t}$. This computes the average probability of correct prediction made by a fitted model. 


\section{Data}

The overall EPU index is constructed from three components: news coverage, federal tax code expiration data, and economic forecaster disagreement. The first component of the EPU index reflects how many articles contain the triple of key words -(1) 'economic' or 'economy', (2) 'uncertain' or 'uncertainty', and (3) one or more of 'deficit', 'Federal Reserve', 'legislation', 'regulation' or 'White House'- in ten leading newspapers. The second component utilizes the Congressional Budget Office (CBO)'s reports that list the expiration dates of temporary federal tax provisions, assuming that temporary tax measures create uncertainty for businesses and households. The third component draws upon the Federal Reserve Bank of Philadelphia's Survey of Professional Forecasters, measuring the dispersion in the forecasts of the consumer price index (CPI) and the purchases of goods and services by the federal, state and local governments. After these components are individually collected each month and indexed over the period starting in January of 1985, the monthly EPU index is constructed by aggregating the components. Technical details are explained in Baker et al. (2016), and the data sets are downloaded from their website ${ }^{1}$.

Baker et al. (2016) also release the nine category-specific EPU indexes. They use over 2,000 US newspapers in the Access World News. Each of the category-specific EPU indexes requires categorical policy terms as well as the triple of the key words used to construct the overall EPU index. The EPU index of monetary policy, for example, reflects how many articles contain the three key words and one of category-specific terms, such as "federal reserve", "money supply", "discount window" and so on. The list of categorical policy terms is on the web site of Baker et al. cited above.

For the financial variables, we source the data series from the FRED of the Federal Reserve Bank of St. Louis ${ }^{2}$. Following Estrella and Mishkin (1998), we use the term and corporate spreads, the stock returns and the stock market volatility. The term spread (TERM) is defined as the difference between the 10-year and 3-month Treasury yields. The corporate spread (CORP) is the Aaa corporate bond yield minus the 10-year Treasury yield. The stock return (RETURN) is calculated as the log difference of the S\&P 500 index from the previous month. The stock market volatility (VOL) is the predicted value from the generalized autoregressive conditional heteroscedasticity $(\mathrm{GARCH})$ model. The $\operatorname{GARCH}(1,1)$ model is estimated with the $\log$ difference of the S\&P 500 index.

Figure 1. Descriptive Statistics.

\begin{tabular}{|c|c|c|c|c|c|}
\hline & mean & median & minimum & maximum & standard deviation \\
\hline EPU - Overall & 107.76 & 100.43 & 57.2 & 245.13 & 32.1 \\
\hline EPU - Monetary Policy & 94.18 & 77.44 & 16.57 & 407.94 & 58 \\
\hline EPU - Taxes & 103.15 & 81.04 & 24.44 & 409.29 & 63.46 \\
\hline EPU - Government Spending & 105.84 & 79.56 & 5.78 & 635.27 & 98.55 \\
\hline EPU - Health Care & 114.25 & 85.29 & 6.86 & 568.71 & 89.33 \\
\hline EPU - National Security & 93.08 & 70.97 & 23.74 & 758.26 & 79.49 \\
\hline EPU - Entitlement Program & 108.8 & 84.22 & 11.05 & 527.59 & 83.7 \\
\hline EPU - Regulation & 104.97 & 92.15 & 28.19 & 384.39 & 54.31 \\
\hline EPU - Trade Policy & 91.46 & 60.06 & 0 & 1094.16 & 106.21 \\
\hline EPU - Soverign Debt / Currency Crisis & 114.21 & 46.39 & 0 & 1502.38 & 197.22 \\
\hline TERM & 1.83 & 1.96 & -0.7 & 3.69 & 1.12 \\
\hline CORP & 1.35 & 1.34 & 0.44 & 2.68 & 0.48 \\
\hline RETURN & 0.65 & 1.06 & -24.54 & 12.38 & 4.38 \\
\hline VOL & 2.1 & 2.06 & 2.04 & 3.13 & 0.1 \\
\hline
\end{tabular}

\footnotetext{
${ }^{1}$ http://www.policyuncertainty.com/.

${ }^{2}$ https://fred.stlouisfed.org/.
} 
The dates of recessions are retrieved from OECD Business Cycle Analysis Database ${ }^{3}$. The sample covers the period from January 1985 to April 2016. Figure 1 provides the descriptive statistics of the variables.

\section{Empirical results}

In this analysis, the linear relationship (1) is specified as:

$$
Y_{t+h}=\beta_{0}+\beta_{1} E P U_{t}+\beta_{2} T E R M_{t}+\beta_{3} C O R P_{t}+\beta_{4} R E T U R N_{t}+\beta_{5} V O L_{t}+\epsilon_{t}
$$

where $E P U_{t}$ is one of the EPU indexes at time t. We estimate the models by maximizing Eq. 4 for forecast horizons from $h=1$ to $h=60$.

Figure 2. The estimated marginal effects on the recession probability along with the $95 \%$ confidence bands.
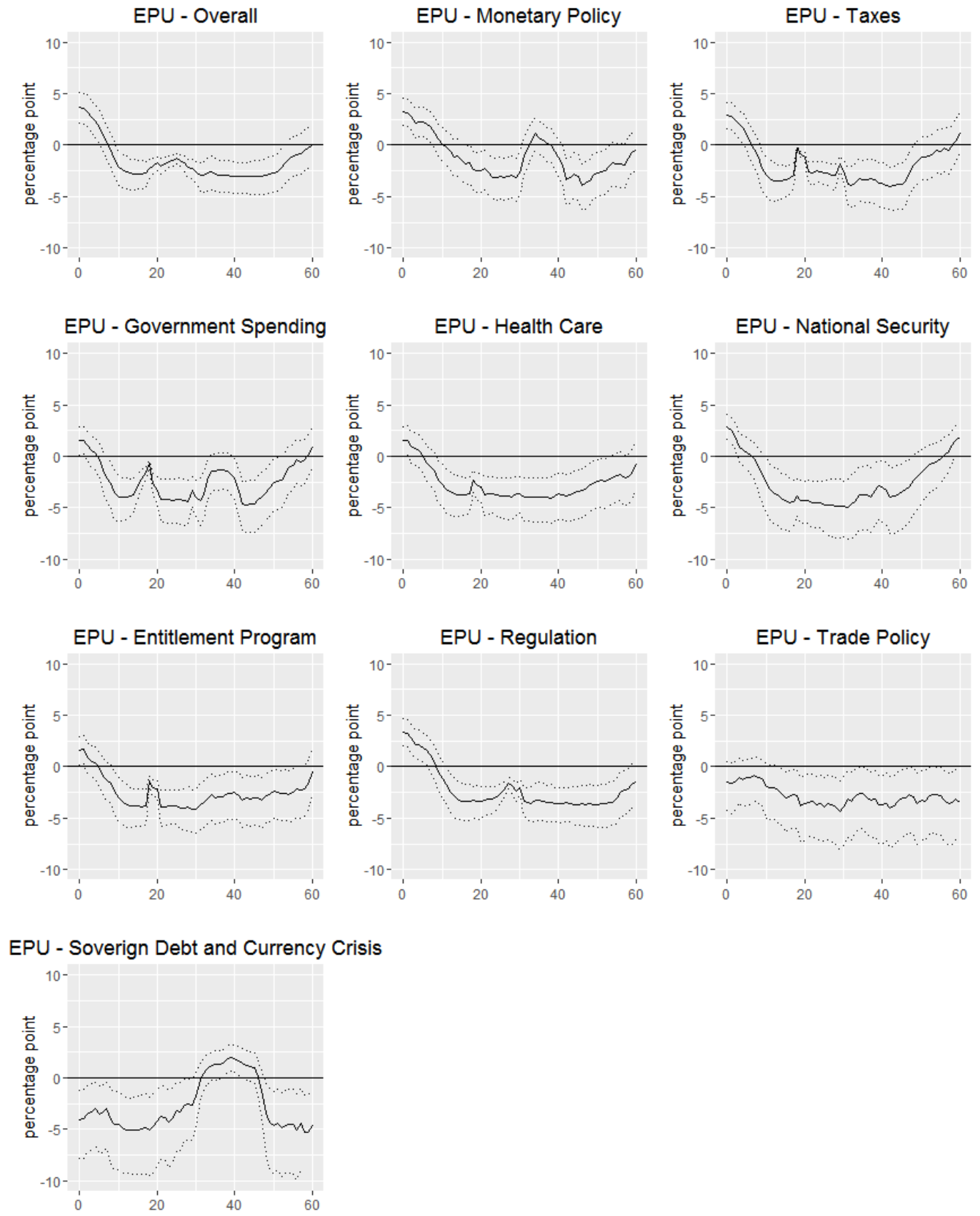

\footnotetext{
${ }^{3} \mathrm{http} / / /$ stats.oecd.org/mei/default.asp?rev=2.
} 
Under the assumption that the EPU indexes increase by one standard deviation at $\mathrm{h}=0$, Figure 2 plots the estimated marginal effects of the EPU indexes on the recession probability, along with the $95 \%$ confidence bands, from $h=1$ to $h=60$. The robust standard errors developed by Estrella and Rodrigues (1998) are used to compute the confidence bands.

Figure 3. Fit measures.

(a) Pseudo $R^{2}$

\begin{tabular}{l|cccccccccccc}
$\mathrm{h}$ & 1 & 2 & 3 & 4 & 5 & 6 & 12 & 18 & 24 & 36 & 48 & 60 \\
\hline No EPU & 0.1098 & 0.1216 & 0.1090 & 0.1099 & 0.1179 & 0.1275 & 0.2215 & 0.3009 & 0.2592 & 0.0906 & 0.0163 & 0.0769 \\
EPU - Overall & $\mathbf{0 . 1 2 6 1}$ & $\mathbf{0 . 1 3 6 6}$ & $\mathbf{0 . 1 1 8 4}$ & $\mathbf{0 . 1 1 8 0}$ & $\mathbf{0 . 1 2 2 6}$ & $\mathbf{0 . 1 2 9 6}$ & $\mathbf{0 . 2 2 4 1}$ & $\mathbf{0 . 3 0 8 4}$ & $\mathbf{0 . 2 9 4 9}$ & $\mathbf{0 . 1 1 4 0}$ & $\mathbf{0 . 0 7 8 0}$ & $\mathbf{0 . 0 7 9 5}$ \\
EPU - Monetary Policy & $\mathbf{0 . 1 4 1 0}$ & $\mathbf{0 . 1 3 7 1}$ & $\mathbf{0 . 1 1 2 1}$ & $\mathbf{0 . 1 1 5 0}$ & $\mathbf{0 . 1 2 3 5}$ & $\mathbf{0 . 1 3 1 1}$ & $\mathbf{0 . 2 2 4 2}$ & $\mathbf{0 . 3 0 6 1}$ & $\mathbf{0 . 2 7 3 5}$ & $\mathbf{0 . 0 9 2 9}$ & $\mathbf{0 . 0 5 0 9}$ & $\mathbf{0 . 0 7 7 0}$ \\
EPU - Taxes & $\mathbf{0 . 1 2 2 5}$ & $\mathbf{0 . 1 2 9 7}$ & $\mathbf{0 . 1 1 2 7}$ & $\mathbf{0 . 1 1 2 9}$ & $\mathbf{0 . 1 1 8 1}$ & $\mathbf{0 . 1 2 8 0}$ & $\mathbf{0 . 2 3 8 3}$ & $\mathbf{0 . 3 6 2 0}$ & $\mathbf{0 . 2 8 1 4}$ & $\mathbf{0 . 1 0 1 4}$ & $\mathbf{0 . 0 2 7 8}$ & $\mathbf{0 . 0 7 9 6}$ \\
EPU - Government Spending & $\mathbf{0 . 1 1 6 2}$ & $\mathbf{0 . 1 2 2 9}$ & $\mathbf{0 . 1 0 9 1}$ & $\mathbf{0 . 1 1 0 0}$ & $\mathbf{0 . 1 1 8 9}$ & $\mathbf{0 . 1 3 4 7}$ & $\mathbf{0 . 2 4 8 0}$ & $\mathbf{0 . 3 8 3 0}$ & $\mathbf{0 . 2 7 2 2}$ & $\mathbf{0 . 0 9 4 4}$ & $\mathbf{0 . 0 5 4 3}$ & $\mathbf{0 . 0 7 8 3}$ \\
EPU - Health Care & $\mathbf{0 . 1 0 9 9}$ & $\mathbf{0 . 1 2 4 7}$ & $\mathbf{0 . 1 1 1 6}$ & $\mathbf{0 . 1 1 1 6}$ & $\mathbf{0 . 1 2 1 5}$ & $\mathbf{0 . 1 3 4 5}$ & $\mathbf{0 . 2 3 8 7}$ & $\mathbf{0 . 3 2 9 1}$ & $\mathbf{0 . 2 6 2 9}$ & $\mathbf{0 . 1 0 7 3}$ & $\mathbf{0 . 0 3 7 3}$ & $\mathbf{0 . 0 8 5 8}$ \\
EPU - National Security & $\mathbf{0 . 1 4 8 0}$ & $\mathbf{0 . 1 4 5 4}$ & $\mathbf{0 . 1 1 1 7}$ & $\mathbf{0 . 1 1 1 4}$ & $\mathbf{0 . 1 1 8 3}$ & $\mathbf{0 . 1 2 7 7}$ & $\mathbf{0 . 2 2 4 2}$ & $\mathbf{0 . 3 5 2 6}$ & $\mathbf{0 . 2 9 3 9}$ & $\mathbf{0 . 1 1 2 8}$ & $\mathbf{0 . 0 3 0 7}$ & $\mathbf{0 . 0 9 5 5}$ \\
EPU - Entitlement Program & $\mathbf{0 . 1 1 0 1}$ & $\mathbf{0 . 1 2 6}$ & $\mathbf{0 . 1 1 5 1}$ & $\mathbf{0 . 1 1 4 8}$ & $\mathbf{0 . 1 2 7 3}$ & $\mathbf{0 . 1 4 7 3}$ & $\mathbf{0 . 2 6 8 6}$ & $\mathbf{0 . 3 6 1 4}$ & $\mathbf{0 . 2 7 4 3}$ & $\mathbf{0 . 0 9 2 6}$ & $\mathbf{0 . 0 3 2 9}$ & $\mathbf{0 . 0 7 7 2}$ \\
EPU - Regulation & $\mathbf{0 . 1 3 9 9}$ & $\mathbf{0 . 1 3 6 5}$ & $\mathbf{0 . 1 1 6 7}$ & $\mathbf{0 . 1 2 2 0}$ & $\mathbf{0 . 1 2 8 8}$ & $\mathbf{0 . 1 4 1 2}$ & $\mathbf{0 . 2 2 1 5}$ & $\mathbf{0 . 3 1 1 5}$ & $\mathbf{0 . 2 9 9 7}$ & $\mathbf{0 . 1 1 9 6}$ & $\mathbf{0 . 0 8 6 3}$ & $\mathbf{0 . 0 8 9 1}$ \\
EPU - Trade Policy & $\mathbf{0 . 1 0 9 9}$ & $\mathbf{0 . 1 2 1 6}$ & $\mathbf{0 . 1 0 9 5}$ & $\mathbf{0 . 1 1 0 0}$ & $\mathbf{0 . 1 1 8 0}$ & $\mathbf{0 . 1 2 7 6}$ & $\mathbf{0 . 2 2 2 6}$ & $\mathbf{0 . 3 0 3 7}$ & $\mathbf{0 . 2 6 9 7}$ & $\mathbf{0 . 1 1 0 6}$ & $\mathbf{0 . 0 3 9 7}$ & $\mathbf{0 . 1 1 4 2}$ \\
EPU - Soverign Debt and Currency Crisis & $\mathbf{0 . 1 5 3 9}$ & $\mathbf{0 . 1 5 9 6}$ & $\mathbf{0 . 1 4 2 2}$ & $\mathbf{0 . 1 3 9 1}$ & $\mathbf{0 . 1 5 7 9}$ & $\mathbf{0 . 1 6 7 0}$ & $\mathbf{0 . 2 9 4 7}$ & $\mathbf{0 . 3 3 9 8}$ & $\mathbf{0 . 2 7 2 4}$ & $\mathbf{0 . 1 0 1 8}$ & $\mathbf{0 . 0 3 0 9}$ & $\mathbf{0 . 1 0 5 0}$
\end{tabular}

(b) The probability of correct prediction

\begin{tabular}{|c|c|c|c|c|c|c|c|c|c|c|c|c|}
\hline $\mathrm{h}$ & 1 & 2 & 3 & 4 & 5 & 6 & 12 & 18 & 24 & 36 & 48 & 60 \\
\hline No EPU & 0.9525 & 0.9541 & 0.9497 & 0.9494 & 0.9503 & 0.9518 & 0.9692 & 0.9869 & 0.9798 & 0.9369 & 0.9213 & 0.9296 \\
\hline EPU - Overall & 0.9539 & 0.9553 & 0.9503 & 0.9505 & 0.9511 & 0.9522 & 0.9692 & 0.9885 & 0.9867 & 0.9416 & 0.9334 & 0.9308 \\
\hline EPU - Monetary Policy & 0.9566 & 0.9555 & 0.9495 & 0.9499 & 0.9515 & 0.9528 & 0.9702 & 0.9882 & 0.9826 & 0.9373 & 0.9275 & 0.9297 \\
\hline EPU - Taxes & 0.9537 & 0.9550 & 0.9504 & 0.9503 & 0.9504 & 0.9517 & 0.9730 & 0.9997 & 0.9829 & 0.9392 & 0.9237 & 0.9295 \\
\hline EPU - Government Spending & 0.9518 & 0.9537 & 0.9496 & 0.9494 & 0.9508 & 0.9533 & 0.9736 & 0.9998 & 0.9831 & 0.9379 & 0.9288 & 0.9295 \\
\hline EPU - Health Care & 0.9526 & 0.9547 & 0.9498 & 0.9492 & 0.9503 & 0.9517 & 0.9722 & 0.9932 & 0.9791 & 0.9392 & 0.9246 & 0.9330 \\
\hline EPU - National Security & 0.9577 & 0.9563 & 0.9492 & 0.9492 & 0.9503 & 0.9518 & 0.9694 & 0.9985 & 0.9880 & 0.9403 & 0.9236 & 0.9333 \\
\hline EPU - Entitlement Program & 0.9524 & 0.9548 & 0.9506 & 0.9498 & 0.9516 & 0.9535 & 0.9792 & 0.9998 & 0.9822 & 0.9371 & 0.9240 & 0.9299 \\
\hline EPU - Regulation & 0.9567 & 0.9564 & 0.9512 & 0.9520 & 0.9528 & 0.9551 & 0.9691 & 0.9890 & 0.9877 & 0.9440 & 0.9330 & 0.9339 \\
\hline EPU - Trade Policy & 0.9525 & 0.9541 & 0.9497 & 0.9494 & 0.9504 & 0.9519 & 0.9692 & 0.9883 & 0.9834 & 0.9412 & 0.9247 & 0.9373 \\
\hline EPU - Soverign Debt and Currency Crisis & 0.9633 & 0.9634 & 0.9575 & 0.9564 & 0.9585 & 0.9596 & 0.9828 & 0.9956 & 0.9834 & 0.9400 & 0.9237 & 0.9339 \\
\hline
\end{tabular}

The marginal effects of the overall EPU index are positive and statistically significant from $\mathrm{h}=1$ to $\mathrm{h}=5$. Thus, an increase in the overall EPU signals higher recessions probability for five months ahead. This finding is consistent with Karnizova and Li (2014), who find that the recession probability rises for next two quarters after an adverse shock shifts up the overall EPU index. In quantitative terms, the overall EPU index raises the recession probability by roughly four percentage points at the maximum at $h=1$. The marginal effects reverse the signs after $h=6$ and remain negative until $h=60$, which indicates that the overall EPU index lowers the recession probability in the long run.

For the category-specific EPU indexes of monetary policy, taxes, national security and regulation, the marginal effects are positive and statistically significant in the short run. These results demonstrate the marginal significance of these policy categories beyond the financial variables. The marginal effects are around two to three percentage points at the maximum, which are slightly smaller than those of the overall index. The sign reversals are also found in Figure 2. The marginal effects become negative around $h=10$ and remain statistically significant in the long run. The sign reversals are consistent with what Bloom (2009) describes as "boom-bust" dynamics of macroeconomic outcomes to uncertainty shocks. In his parameterized model, an uncertainty shock triggers a recession, which is followed by a recovery. Thus, these EPU indexes help predict recession and subsequent recovery. The other five category-specific EPU indexes are statistically insignificant in the short run. These variables, thus, have little information about the occurrence of recession that have not already been incorporated in the financial variables

Figure 3 reports the fit measures for the different forecast horizons. For comparison, the tables also report the fit measures of the models with the financial variables alone as benchmarks. The models that outperform these benchmarks are in bold.

In Figure 3(a), the pseudo $R^{2}$ 's are all higher than the benchmarks because any additional variable improves the coefficient of determination. The EPU indexes of national security, 
regulation, and sovereign debt and currency crisis predict recession relatively well in comparison with the overall EPU index.

In Figure 3(b), most, but not all, of the EPU indexes improve the probability of correct prediction, particularly in the long run. The increments from the benchmark models, however, are not noticeably large since the benchmarks can predict recession very accurately even without any information from the EPU indexes. As it is for the pseudo $R^{2}$, the EPU indexes of national security, regulation, and sovereign debt and currency crisis yield more accurate predictions than the overall and other category-specific EPU indexes.

Figure 4. Results from joint estimation.

\begin{tabular}{|c|c|c|c|c|c|c|c|c|c|c|c|}
\hline h & 1 & 2 & 3 & 4 & 5 & 6 & 12 & 24 & 36 & 48 & 60 \\
\hline Intercept & $-5.011^{* *}$ & $-5.011 * *$ & $-5.006^{* *}$ & $-4.995^{* *}$ & $-4.993^{* *}$ & $-4.977^{* * *}$ & $-4.966^{* * *}$ & $-4.809^{* * *}$ & $-5.199 * *$ & $-5.596 * *$ & $-5.310^{* * *}$ \\
\hline (s.e.) & (1.178) & $(1.176)$ & $(1.176)$ & $(1.176)$ & (1.176) & (1.173) & $(1.165)$ & (1.167) & $(1.528)$ & (1.623) & (1.61) \\
\hline EPU - Monetary Policy & -0.001 & -0.001 & -0.001 & -0.001 & -0.001 & -0.001 & -0.001 & 0.000 & 0.005 & 0.008 & 0.007 \\
\hline (s.e.) & $(0.004)$ & $(0.004)$ & $(0.004)$ & $(0.004)$ & $(0.004)$ & $(0.004)$ & $(0.004)$ & $(0.004)$ & $(0.005)$ & $(0.005)$ & $(0.005)$ \\
\hline EPU - Taxes & -0.007 & -0.007 & -0.007 & -0.007 & -0.007 & -0.006 & -0.006 & 0.000 & 0.001 & 0.002 & 0.002 \\
\hline (s.e.) & $(0.006)$ & $(0.006)$ & $(0.006)$ & $(0.006)$ & $(0.006)$ & $(0.006)$ & $(0.006)$ & $(0.006)$ & $(0.007)$ & $(0.007)$ & $(0.007)$ \\
\hline EPU - Government Spending & 0.000 & 0.000 & 0.000 & 0.000 & 0.000 & 0.000 & 0.000 & 0.003 & 0.007 & 0.009 & 0.009 \\
\hline (s.e.) & $(0.003)$ & $(0.003)$ & $(0.003)$ & $(0.003)$ & $(0.003)$ & $(0.003)$ & $(0.003)$ & $(0.003)$ & $(0.004)$ & $(0.004)$ & $(0.004)$ \\
\hline EPU - Health Care & -0.008 & -0.008 & -0.008 & -0.008 & -0.008 & -0.008 & -0.009 & -0.013 & $-0.017^{*}$ & $-0.019^{*}$ & $-0.019^{*}$ \\
\hline (s.e.) & $(0.004)$ & $(0.004)$ & $(0.004)$ & $(0.004)$ & $(0.004)$ & $(0.004)$ & $(0.004)$ & $(0.004)$ & $(0.005)$ & $(0.005)$ & $(0.005)$ \\
\hline EPU - National Security & $-0.004^{*}$ & $-0.004^{*}$ & $-0.004^{*}$ & $-0.004^{*}$ & $-0.004^{*}$ & $-0.004^{*}$ & $-0.004^{*}$ & $-0.006^{* * *}$ & $-0.008^{* * *}$ & $-0.009^{* * *}$ & $-0.009^{* * *}$ \\
\hline (s.e.) & $(0.002)$ & $(0.002)$ & $(0.002)$ & $(0.002)$ & $(0.002)$ & $(0.002)$ & $(0.002)$ & $(0.002)$ & $(0.002)$ & $(0.003)$ & $(0.003)$ \\
\hline EPU - Entitlement Program & 0.000 & 0.000 & 0.000 & 0.000 & 0.000 & 0.000 & $0.000^{*}$ & $-0.001^{* *}$ & $-0.003^{* * *}$ & $-0.004^{* *}$ & $-0.004^{* *}$ \\
\hline (s.e.) & $(0.003)$ & $(0.003)$ & $(0.003)$ & $(0.003)$ & $(0.003)$ & $(0.003)$ & $(0.003)$ & $(0.003)$ & $(0.004)$ & $(0.004)$ & $(0.004)$ \\
\hline EPU - Regulation & 0.010 & 0.010 & 0.010 & 0.010 & 0.010 & 0.010 & 0.010 & 0.013 & 0.016 & 0.018 & 0.018 \\
\hline (s.e.) & $(0.004)$ & $(0.004)$ & $(0.004)$ & $(0.004)$ & $(0.004)$ & $(0.004)$ & $(0.004)$ & $(0.005)$ & $(0.005)$ & $(0.005)$ & $(0.005)$ \\
\hline EPU - Trade Policy & $-0.001^{*}$ & $-0.001 *$ & $-0.001^{*}$ & $-0.001^{*}$ & $-0.001^{*}$ & $-0.001 *$ & $-0.002^{*}$ & $-0.001^{* * *}$ & $0.000^{* *}$ & $0.000^{* * *}$ & $0.000^{* * *}$ \\
\hline (s.e.) & $(0.003)$ & $(0.003)$ & $(0.003)$ & $(0.003)$ & $(0.003)$ & $(0.003)$ & $(0.003)$ & $(0.003)$ & $(0.003)$ & $(0.003)$ & $(0.003)$ \\
\hline EPU -Soveriegn Debt / Currency Crisis & $-0.008^{* *}$ & $-0.008^{* * *}$ & $-0.008^{* *}$ & $-0.008^{* *}$ & $-0.008^{* * *}$ & $-0.008^{* *}$ & $-0.008^{* *}$ & $-0.010^{* * *}$ & $-0.011^{* * *}$ & $-0.010^{* *}$ & $-0.011^{* *}$ \\
\hline (s.e.) & $(0.002)$ & $(0.002)$ & $(0.002)$ & $(0.002)$ & $(0.002)$ & $(0.002)$ & $(0.002)$ & $(0.003)$ & $(0.003)$ & $(0.003)$ & $(0.003)$ \\
\hline TERM & -0.253 & -0.251 & -0.250 & -0.248 & -0.248 & -0.242 & -0.240 & $-0.304 *$ & -0.207 & -0.130 & -0.196 \\
\hline (s.e.) & $(0.134)$ & $(0.134)$ & $(0.134)$ & $(0.135)$ & $(0.135)$ & $(0.136)$ & $(0.136)$ & $(0.140)$ & $(0.148)$ & $(0.151)$ & $(0.161)$ \\
\hline CORP & $1.609 * *$ & $1.605^{* * *}$ & $1.601^{* *}$ & $1.595^{* * *}$ & $1.594 * *$ & $1.573^{* * *}$ & $1.559^{* *}$ & $1.850^{* * *}$ & $2.076^{* *}$ & $2.071^{* * *}$ & $2.045^{* *}$ \\
\hline (s.e.) & $(0.411)$ & $(0.412)$ & $(0.414)$ & $(0.414)$ & $(0.414)$ & $(0.418)$ & $(0.418)$ & $(0.464)$ & $(0.512)$ & $(0.521)$ & $(0.531)$ \\
\hline RETURN & 0.012 & 0.012 & 0.012 & 0.012 & 0.012 & 0.012 & 0.014 & 0.030 & 0.006 & 0.007 & 0.012 \\
\hline (s.e.) & $(0.025)$ & $(0.025)$ & $(0.025)$ & $(0.025)$ & $(0.025)$ & $(0.025)$ & $(0.025)$ & $(0.027)$ & $(0.031)$ & $(0.032)$ & $(0.033)$ \\
\hline VOL & -0.093 & -0.092 & -0.092 & -0.092 & -0.093 & -0.089 & -0.085 & -0.186 & -0.202 & -0.163 & -0.196 \\
\hline (s.e.) & $(0.265)$ & $(0.264)$ & $(0.264)$ & $(0.264)$ & $(0.264)$ & $(0.263)$ & $(0.261)$ & $(0.264)$ & $(0.373)$ & $(0.380)$ & $(0.383)$ \\
\hline
\end{tabular}

Notes: ** if $\mathrm{p}$ value $<0.01 . * *$ if $\mathrm{p}$ value $<0.05$

Figure 4 reports the estimated coefficients and their standard errors from the joint estimation of the probit models with all the category-specific EPU indexes as independent variables:

$$
Y_{t+h}=\beta_{0}+\sum_{i=1}^{9} \beta_{1, i} E P U_{i, t}+\beta_{2} \text { TERM }_{t}+\beta_{3} \operatorname{CORP}_{t}+\beta_{4} \operatorname{RETURN}_{t}+\beta_{5} \operatorname{VOL}_{t}+\epsilon_{t}
$$

where $E P U_{i, t}$ is the ith category-specific EPU index and $\beta_{1, i}$ is its coefficient. These results indicate the marginal predictive power that each category-specific index has over all the other variables.

Among the categories that predict recession relatively well in separate estimation, national security and sovereign debt / currency crisis are statistically significant, indicating that they have information that all the other EPU indexes and the financial variables do not. Regulation is, however, statistically insignificant at all the forecasting horizons.

Figure 5 summarizes the out-of-sample fit measures for the different forecast horizons. In evaluating out-of-sample performance, we recursively estimate the models and make predictions for the periods from January 1995 to April 2011. The models that outperform these benchmarks with the financial variables alone are in bold. Table 4.a shows that most of the pseudo $R^{2}$ 's are less than zero, which indicates that almost all the probit forecasting models, 
including the benchmark models with the financial variables alone, are worse than a constant by itself. An exception is the EPU index of national security at longer forecasting horizons after $h=12$. In comparison with the benchmark models, however, all the EPU indexes improve the pseudo $R^{2}$. In Tables 4.b, the models with and without the EPU indexes predict recession equally well. In the short run, some of the EPU indexes increases the probability of correct prediction by more than one percentage point. The differences are negligibly small in the long run.

Figure 5. Out-of-sample fit measures.

(a) Pseudo $R^{2}$

\begin{tabular}{l|ccccccccccc} 
& 1 & 2 & 3 & 4 & 5 & 6 & 12 & 24 & 36 & 48 & 60 \\
\hline No EPU & -0.2887 & -0.4294 & -0.6274 & -1.0261 & -1.4083 & -1.5865 & -2.1504 & -13.2787 & -1.4885 & -1.1703 & -0.6592 \\
EPU - Overall & -1.1875 & -1.2848 & -0.6897 & $\mathbf{- 0 . 2 7 4 7}$ & $\mathbf{- 0 . 0 9 6 9}$ & $\mathbf{0 . 0 0 1 3}$ & $\mathbf{- 0 . 1 7 3 1}$ & $\mathbf{- 1 . 5 8 7 3}$ & $\mathbf{- 0 . 3 9 6 9}$ & $\mathbf{- 0 . 4 2 2 3}$ & -0.9963 \\
EPU - Monetary Policy & -0.3432 & $\mathbf{- 0 . 2 2 7 6}$ & $\mathbf{- 0 . 0 8 9 0}$ & $\mathbf{- 0 . 0 6 5 7}$ & $\mathbf{- 0 . 0 4 3 9}$ & $\mathbf{- 0 . 0 2 4 4}$ & $\mathbf{- 0 . 0 1 1 6}$ & $\mathbf{- 0 . 0 2 8 9}$ & $\mathbf{- 0 . 1 4 9 3}$ & $\mathbf{- 0 . 0 1 3 2}$ & $\mathbf{0 . 0 0 6 1}$ \\
EPU - Taxes & -0.5625 & $\mathbf{- 0 . 3 6 3 5}$ & $\mathbf{- 0 . 1 6 9 6}$ & $\mathbf{- 0 . 1 1 7 4}$ & $\mathbf{- 0 . 0 3 5 4}$ & $\mathbf{0 . 0 2 9 6}$ & $\mathbf{- 0 . 2 7 0 1}$ & $\mathbf{- 0 . 8 2 0 2}$ & $\mathbf{- 0 . 1 7 9 1}$ & $\mathbf{- 0 . 2 2 3 1}$ & $\mathbf{- 0 . 0 5 4 3}$ \\
EPU - Government Spending & -0.6405 & $\mathbf{- 0 . 3 9 6 8}$ & $\mathbf{- 0 . 2 6 2 9}$ & $\mathbf{- 0 . 2 2 4 4}$ & $\mathbf{- 0 . 1 4 2 7}$ & $\mathbf{- 0 . 0 5 0 7}$ & $\mathbf{- 0 . 1 9 3 4}$ & $\mathbf{- 0 . 1 1 0 9}$ & $\mathbf{- 0 . 3 0 8 6}$ & $\mathbf{- 0 . 0 7 3 9}$ & $\mathbf{- 0 . 1 6 7 3}$ \\
EPU - Health Care & $-\mathbf{0 . 0 0 9 6}$ & $\mathbf{0 . 0 8 7 1}$ & $\mathbf{0 . 1 0 4 5}$ & $\mathbf{0 . 1 0 5 0}$ & $\mathbf{0 . 1 0 2 8}$ & $\mathbf{0 . 0 5 5 5}$ & $\mathbf{- 0 . 2 7 1 2}$ & $\mathbf{- 0 . 7 1 7 3}$ & $\mathbf{- 0 . 5 4 0 6}$ & $\mathbf{- 0 . 0 2 7 3}$ & $\mathbf{- 0 . 0 1 3 4}$ \\
EPU - National Security & -2.1553 & -1.2243 & $\mathbf{- 0 . 2 4 5 6}$ & $\mathbf{- 0 . 1 7 6 0}$ & $\mathbf{- 0 . 1 1 2 6}$ & $\mathbf{- 0 . 0 8 1 0}$ & $\mathbf{0 . 0 4 5 8}$ & $\mathbf{0 . 1 0 7 0}$ & $\mathbf{0 . 0 8 2 2}$ & $\mathbf{0 . 1 7 1 7}$ & $\mathbf{0 . 0 4 2 6}$ \\
EPU - Entitlement Program & $-\mathbf{0 . 0 7 4 5}$ & $\mathbf{- 0 . 0 0 2 0}$ & $\mathbf{- 0 . 0 0 1 7}$ & $\mathbf{- 0 . 0 0 4 6}$ & $\mathbf{0 . 0 0 0 3}$ & $\mathbf{- 0 . 2 0 0 5}$ & $\mathbf{- 0 . 4 7 3 4}$ & $\mathbf{- 0 . 6 4 4 4}$ & $\mathbf{- 0 . 0 5 0 4}$ & $\mathbf{- 0 . 1 0 3 1}$ & $\mathbf{- 0 . 0 2 6 8}$ \\
EPU - Regulation & -0.5170 & $\mathbf{- 0 . 2 0 6 2}$ & $\mathbf{- 0 . 0 9 4 2}$ & $\mathbf{- 0 . 1 3 1 0}$ & $\mathbf{- 0 . 1 3 0 5}$ & $\mathbf{- 0 . 1 5 4 1}$ & $\mathbf{- 0 . 0 7 4 3}$ & $\mathbf{- 1 . 0 4 3 3}$ & $\mathbf{- 0 . 4 1 3 7}$ & $\mathbf{- 0 . 3 6 1 5}$ & $\mathbf{- 0 . 0 0 2 0}$ \\
EPU - Trade Policy & $\mathbf{0 . 0 5 2 4}$ & $\mathbf{0 . 0 4 0 2}$ & $\mathbf{0 . 0 1 8 9}$ & $\mathbf{0 . 0 3 6 0}$ & $\mathbf{0 . 0 4 2 0}$ & $\mathbf{0 . 0 3 9 9}$ & $\mathbf{0 . 1 0 1 8}$ & $\mathbf{0 . 0 8 2 4}$ & $\mathbf{0 . 0 9 4 6}$ & $\mathbf{0 . 1 2 3 6}$ & $\mathbf{0 . 0 4 4 6}$ \\
EPU - Soverign Debt and Currency Crisis & -0.4128 & $\mathbf{- 0 . 2 8 4 6}$ & $\mathbf{- 0 . 1 9 6 0}$ & $\mathbf{- 0 . 1 0 5 2}$ & $\mathbf{- 0 . 6 2 0 4}$ & $\mathbf{- 0 . 6 8 3 6}$ & $\mathbf{- 1 . 1 6 7 6}$ & $\mathbf{- 0 . 0 7 4 6}$ & $\mathbf{0 . 0 7 5 3}$ & $\mathbf{- 0 . 0 6 5 2}$ & $\mathbf{- 0 . 0 9 5 2}$
\end{tabular}

(b) The probability of correct prediction

\begin{tabular}{l|ccccccccccc} 
& 1 & 2 & 3 & 4 & 5 & 6 & 12 & 24 & 36 & 48 \\
\hline No EPU & 0.8923 & 0.8856 & 0.8803 & 0.8760 & 0.8722 & 0.8691 & 0.8913 & 0.8555 & 0.8624 & 0.9597 & 0.8999 \\
EPU - Overall & $\mathbf{0 . 9 0 9 6}$ & $\mathbf{0 . 9 0 6 4}$ & $\mathbf{0 . 9 0 0 5}$ & $\mathbf{0 . 8 9 8 9}$ & $\mathbf{0 . 8 9 6 0}$ & $\mathbf{0 . 8 9 1 6}$ & 0.8732 & $\mathbf{0 . 8 6 6 7}$ & $\mathbf{0 . 8 6 7 7}$ & 0.8683 & 0.8836 \\
EPU - Monetary Policy & 0.8724 & 0.8736 & 0.8756 & 0.8758 & $\mathbf{0 . 8 7 6 2}$ & $\mathbf{0 . 8 7 7 2}$ & 0.8820 & $\mathbf{0 . 8 8 5 0}$ & $\mathbf{0 . 8 8 0 2}$ & 0.8906 & 0.8882 \\
EPU - Taxes & 0.8828 & 0.8822 & $\mathbf{0 . 8 8 1 9}$ & $\mathbf{0 . 8 8 1 6}$ & $\mathbf{0 . 8 8 1 3}$ & $\mathbf{0 . 8 8 1 5}$ & 0.8767 & $\mathbf{0 . 8 7 0 8}$ & $\mathbf{0 . 8 7 5 3}$ & 0.8774 & 0.8894 \\
EPU - Government Spending & 0.8732 & 0.8741 & 0.8748 & 0.8751 & $\mathbf{0 . 8 7 5 9}$ & $\mathbf{0 . 8 7 7 3}$ & 0.8772 & $\mathbf{0 . 8 7 7 9}$ & $\mathbf{0 . 8 7 6 4}$ & 0.8817 & 0.8818 \\
EPU - Health Care & $\mathbf{0 . 9 0 2 9}$ & $\mathbf{0 . 8 9 6 7}$ & $\mathbf{0 . 8 9 4 4}$ & $\mathbf{0 . 8 9 3 1}$ & $\mathbf{0 . 8 8 9 9}$ & $\mathbf{0 . 8 8 6 1}$ & 0.8716 & $\mathbf{0 . 8 6 8 2}$ & $\mathbf{0 . 8 6 9 8}$ & 0.8801 & 0.8931 \\
EPU - National Security & 0.8675 & 0.8690 & 0.8742 & 0.8754 & $\mathbf{0 . 8 7 6 9}$ & $\mathbf{0 . 8 7 8 0}$ & 0.8861 & $\mathbf{0 . 8 9 7 5}$ & $\mathbf{0 . 8 9 1 0}$ & 0.9014 & 0.8866 \\
EPU - Entitlement Program & 0.8864 & 0.8827 & $\mathbf{0 . 8 8 1 4}$ & $\mathbf{0 . 8 8 1 2}$ & $\mathbf{0 . 8 8 0 5}$ & $\mathbf{0 . 8 7 9 0}$ & 0.8736 & $\mathbf{0 . 8 7 1 5}$ & $\mathbf{0 . 8 7 9 5}$ & 0.8802 & 0.8868 \\
EPU - Regulation & $\mathbf{0 . 9 0 1 2}$ & $\mathbf{0 . 8 9 5 6}$ & $\mathbf{0 . 8 9 2 2}$ & $\mathbf{0 . 8 9 2 0}$ & $\mathbf{0 . 8 8 9 9}$ & $\mathbf{0 . 8 8 8 3}$ & 0.8751 & $\mathbf{0 . 8 6 9 2}$ & $\mathbf{0 . 8 6 8 9}$ & 0.8779 & 0.8857 \\
EPU - Trade Policy & 0.8838 & 0.8832 & $\mathbf{0 . 8 8 1 9}$ & $\mathbf{0 . 8 8 3 0}$ & $\mathbf{0 . 8 8 3 1}$ & $\mathbf{0 . 8 8 3 1}$ & 0.8888 & $\mathbf{0 . 8 9 2 8}$ & $\mathbf{0 . 8 9 4 9}$ & 0.9010 & $\mathbf{0 . 9 0 4 0}$ \\
EPU - Soverign Debt and Currency Crisis & 0.8756 & 0.8759 & 0.8764 & $\mathbf{0 . 8 7 7 2}$ & $\mathbf{0 . 8 7 5 5}$ & $\mathbf{0 . 8 7 5 5}$ & 0.8766 & $\mathbf{0 . 8 8 0 2}$ & $\mathbf{0 . 8 8 8 2}$ & 0.8834 & 0.8880
\end{tabular}

\section{Concluding remarks}

This paper has examined the potential use of the category-specific EPU indexes to predict US recession. We have estimated the probit forecasting models to quantify the marginal significance of the EPU indexes beyond the financial variables. Judging from the in-sample separate and multiple estimation and the out-of-sample performance, the category-specific EPU index of national security has been found relatively useful as predictors of recession. This measure of uncertainty provides information about the occurrence of recession that the financial variables do not contain.

One can speculate on economic reasons why national security can help predict future recession. Military spending, which accounts for a large share of the US economy, temporarily shifts aggregate demand upward and generate boom-bust cycles (F-de-Córdoba and Torres (2016)). Because this paper only evaluates the predictive power of the EPU indexes from a statistical perspective, the structural links between this specific policy area and macroeconomic aggregates should be examined more in detail by further studies.

In concluding, the limitations of this study should be borne in mind. In the literature, the EPU indexes have been widely used as proxy variables for policy uncertainty. The indexes are, however, not direct measures of policy uncertainty, drawing only upon newspaper coverage. Thus, it cannot be denied that the indexes are weak proxies, which possibly measure other risk factors as well. Another limitation is that the sample period is relatively short since the EPU index only covers 184 months at the time of writing this paper. These limitations should be overcome through improvements in methodology and data collection. 


\section{References}

Alexopoulos, M., and Cohen, J. (2009) Uncertain times, uncertain measures, University of Toronto Department of Economics Working Paper, 352.

Baker, S. R., Bloom, N., and Davis, S. J. (2016) Measuring economic policy uncertainty, The Quarterly Journal of Economics, 131(4), 1593-1636.

Ben-Akiva, M. E., and Lerman, S. R. (1985) Discrete choice analysis: theory and application to travel demand (Vol. 9), MIT press.

Bernanke, B. S. (1983) Irreversibility, uncertainty, and cyclical investment, The Quarterly Journal of Economics, 98(1), 85-106.

Bluedorn, J. C., Decressin, J., and Terrones, M. E. (2016) Do asset price drops foreshadow recessions?, International Journal of Forecasting, 32(2), 518-526.

Bloom, N. (2009) The impact of uncertainty shocks, Econometrica, 77(3), 623-685.

Born, B., Peter, A., and Pfeifer, J. (2013) Fiscal news and macroeconomic volatility, Journal of Economic Dynamics and Control, 37(12), 2582-2601.

Boudoukh, J., Feldman, R., Kogan, S., and Richardson, M. (2013) Which news moves stock prices? a textual analysis (No. w18725), National Bureau of Economic Research.

Brennan, M. J., and Schwartz, E. S. (1985) Evaluating natural resource investments, Journal of business, 135-157.

Dixit, A. K., and Pindyck, R. S. (1994) Investment under uncertainty, Princeton University Press.

Engle, R. F., and Rangel, J. G. (2008) The spline-GARCH model for low-frequency volatility and its global macroeconomic causes, The Review of Financial Studies, 21(3), 11871222.

Estrella, A., and Rodrigues, A. P. (1998) Consistent covariance matrix estimation in probit models with autocorrelated errors.

Estrella, A., and Mishkin, F. S. (1998) Predicting US recessions: Financial variables as leading indicators, The Review of Economics and Statistics, 80(1), 45-61.

F-de-Córdoba, G., and Torres, J. L. (2016) National security, military spending and the business cycle, Defence and Peace Economics, 27(4), 549-570.

Fernandez-Villaverde, J., and Krueger, D. (2011) Consumption and saving over the life cycle: How important are consumer durables?, Macroeconomic dynamics, 15(5), 725-770.

Gentzkow, M., and Shapiro, J. M. (2010) What drives media slant? Evidence from US daily newspapers, Econometrica, 78(1), 35-71.

Handley, K., and Limão, N. (2013) Policy uncertainty, trade and welfare: theory and evidence for China and the US (No. w19376), National Bureau of Economic Research.

Hoberg, G., and Phillips, G. (2010) Product market synergies and competition in mergers and acquisitions: A text-based analysis, The Review of Financial Studies, 23(10), 3773-3811.

Jones, P. M., and Olson, E. (2013) The time-varying correlation between uncertainty, output, and inflation: Evidence from a DCC-GARCH model, Economics Letters, 118(1), 33-37.

Karnizova, L., and Li, J. C. (2014) Economic policy uncertainty, financial markets and probability of US recessions, Economics Letters, 125(2), 261-265.

Kay, R., and Little, S. (1986) Assessing the fit of the logistic model: a case study of children with the haemolytic uraemic syndrome, Applied Statistics, 16-30.

Liu, W., \& Moench, E. (2016) What predicts US recessions?, International Journal of Forecasting, 32(4), 1138-1150.

McDonald, R., and Siegel, D. (1986) The value of waiting to invest, The Quarterly Journal of Economics, 101(4), 707-727.

NBER's Business Cycle Dating Committee. (2010) Definition of recession, retrieved from http://www.nber.org/cycles/recessions.html. 
Nickell, S. J. (1986) Dynamic models of labour demand, Handbook of labor economics, 1, 473522.

Novy, D., and Taylor, A. M. (2014) Trade and uncertainty (No. w19941), National Bureau of Economic Research.

Nyberg, H. (2018) Forecasting US interest rates and business cycle with a nonlinear regime switching VAR model, Journal of Forecasting, 37(1), 1-15.

OECD (2013) Definition of business cycle, retrieved from https://stats.oecd.org/glossary/detail.asp?ID=244.

Wheelock, D. C., and Wohar, M. E. (2009) Can the term spread predict output growth and recessions? A survey of the literature, Federal Reserve Bank of St. Louis Review, 91(5 Part 1), 419-44 